\title{
Climate Change Effects on Drought in Sharjah, UAE
}

\author{
Abdullah G. Yilmaz, Arwa Najah, Aysha Hussein, Athra Khamis, Naseraldin Kayemah, and Serter \\ Atabay
}

\begin{abstract}
Drought is a natural phenomenon that occurs due to low precipitation conditions. Under the effect of climate change, frequency and magnitude of drought events are aggravated. Drought has negative effects on various fields such as agriculture, environment, ecosystems, economy and society. In this study, drought conditions in Sharjah, United Arab Emirates, were assessed by monthly Rainfall Anomaly Index (RAI) and Aridity Index (AI) using observed and future (projected) rainfall data. Following calculation of the index values, temporal trends were investigated using non-parametric Mann-Kendal trend test. Trend results showed mostly statistically non-significant trends in Sharjah. Only decreasing trends in March was statistically significant for observed RAI values and projected (future) RAI values derived from rainfall data using global climate models including GISS_E2_H, GISS_E2_R and MRI_CGCM3. This study is an outcome of initial stage of a comprehensive drought assessment project, and provides useful information for policymakers in Sharjah, UAE.
\end{abstract}

Index Terms-Climate change, drought, RAI, AI, Sharjah, United Arab Emirates.

\section{INTRODUCTION}

Drought is a complex natural phenomenon that results in serious economic, environmental, and social impacts. The effects of drought accumulate slowly and it affects larger geographical area than any other natural hazards [1]. Drought defined as shortage of water, adversely influences the ecosystems, environment and residents of impacted regions through decrease in crop production, hydropower generation, industry and health. Drought is causing an average \$6- \$8 billion global damage annually and collectively affecting more people than other natural disasters [2].

There are several reasons behind the drought mechanics. Droughts take place when there are prolonged periods of rainfall non-presence leading decreases in streamflows and water levels in natural and man-made reservoirs. In addition, human activities including deforestation, construction, and agriculture negatively impact the water cycle and cause droughts. Soil moisture levels are also contributor to the drought events [3].

Over the last century, earth is warming in a way, which can't be explained by natural climate variability. The main

Manuscript received May 12, 2019; revised January 2, 2020

Abdullah Gokhan Yilmaz is with University of Sharjah, Australia (e-mail: ayilmaz@sharjah.ac.ae).

Arwa Najah and Naseraldin Kayemah are with University of Sharjah, Iraq (e-mail: U15100020@sharjah.ac.ae, U18200520@sharjah.ac.ae).

Aysha Hussein and Athra Khamis are with University of Sharjah, United Arab Emirates (e-mail: U15100400@sharjah.ac.ae, U15104029@sharjah.ac.ae).

Serter Atabay is with American University of Sharjah, United Kingdom, (e-mail: Satabay@aus.edu). reason behind current global warming is greenhouse gases (GHG) emission due to human activities. Warming on earth surface results in change in climate variables such as precipitation, humidity and wind speed. Changes in precipitation amount and patterns along with alterations in other climate variables affect streamflows, and consequently flood and drought management. Risk of all types of drought (i.e., meteorological, hydrological and agricultural) increases as temperatures rise and precipitation amount and patterns change due to global warming. Therefore, it is significant to project (future) droughts to develop efficient future drought management policies.

There are several studies regarding climate change effects on droughts in the literature. For example, [4] investigated drought hazard in South Korea in the context of climate change. This study reported higher risk levels for future drought frequency and intensity in South Korea. Reference [5] reported that the annual drought severity increases due to climate change are projected in Greece for future time scales of 2020-2050 and 2070-2100.

The Middle East and North Africa (MENA) region is one of the most climate change sensitive regions in the world. Reference [6] reported that that the MENA region will likely experience a decrease in rainfall and runoff between 10 and $25 \%$, and between 10 and $40 \%$, respectively, and an increase in evaporation between 5 and $20 \%$ by the end of the $21 \mathrm{st}$ century. Gulf Cooperation Council (GCC) countries are the most climate change fragile regions in MENA due to very intense water stress and droughts. The United Arab Emirates (UAE) is located in GCC region with annual precipitation below $100 \mathrm{~mm}$. According to climate models, an increase in the UAE's annual average temperature of around $1^{\circ} \mathrm{C}$ by 2020 , and $1.5-2^{\circ} \mathrm{C}$ by 2040 was projected [7].

Although droughts have major effects on many aspects in UAE, there are only few studies investigating droughts in UAE. Reference [8] showed the effects of El Niño and La Niña on weather patterns and in particular on rainfall in UAE. They adopted effective drought index to quantify droughts, and reported close relationship between El Niño and droughts in UAE. Reference [9] conducted an analysis of rainfall and drought in the UAE, and found that the average drought duration is about 2.8 years in UAE. Also, they reported similar drought patterns over UAE using drought severity index. To the knowledge of authors, there is no study for UAE investigating climate change effects on droughts using projected (future climate data). In this paper, climate change effects on droughts in Sharjah, which is the third largest of the seven emirates in UAE, were investigated through quantification of the droughts by Rainfall Anomaly Index (RAI) and aridity index (AI) using observed and (future) projected rainfall data in Sharjah, and application of trend analysis to observed and projected RAI values. It is expected that this study will make contribution to the climate 
change-drought literature as well as to the successful drought management in the study area.

\section{STUdy AREA AND DATA}

The Sharjah Emirate in UAE has a total population of 1.4 million and covers an area of approximately $2,600 \mathrm{~km}^{2}$. It falls on coordinates of $25.3^{\circ} \mathrm{N} 55.5^{\circ} \mathrm{E}$ and located along the southern coast of the Arabian Gulf on the Arabian Peninsula. Sharjah is classified as a dessert with hot climate and characterized with its great arid land. Sharjah has mean temperature of $18-34^{\circ} \mathrm{C}$. Rain in Sharjah occur lightly and infrequently with an average of $100 \mathrm{~mm} /$ year. The rainfall season occurs from November to March, and about two-thirds of the annual rainfall concentrates between February and March. Location of Sharjah is shown in Fig. 1.
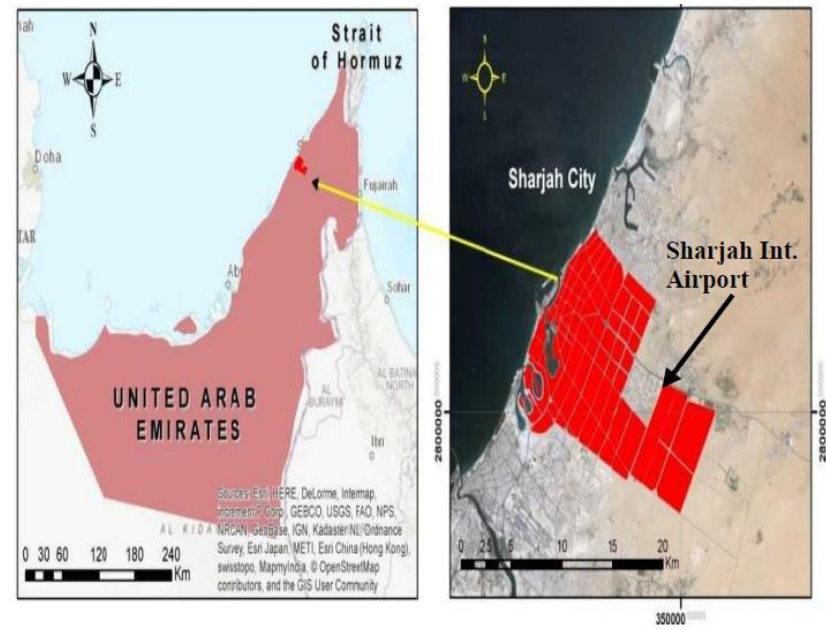

Fig. 1. Location of Sharjah and Sharjah International Airport station.

Two types of monthly precipitation data sets were used in this study:

- Observed monthly rainfall data over the period of 1981 to 2015.

- Future (projected) monthly rainfall data from Global Climate Models (GCMs) for two different periods: near future for the period of 2030-2064 and far future for the period of 2065-2099.

Observed data were received from weather observation station at the Sharjah International Airport. Future data projections were obtained from four GCMs including NASA Goddard Institute for Space Sciences E2 models (GISS_E2_H and GISS_E2_R), Meteorological Research Institute model (MRI_CGCM3), and atmospheric coupled chemistry version of the MIROC_ESM model (MIROC_ESM_CHEM) (as recommended by [10]) listed in Coupled Model Intercomparing Project phase 5 (CMIP5) platform under different scenarios (Representative Concentration Pathways (RCPs)) including RCPs 2.6, 4.5, 6 and 8.5. RCP 2.6 represents the lowest GHG emission scenario, whereas RCP 8.5 represents the highest GHG emission scenario. Detailed explanation of RCPs can be seen in [11].

\section{MethodolOGY}

There are two main parts of the methodology: 1) calculation of monthly RAIs and AIs using observed and projected rainfall data, and 2) trend analysis of calculated monthly RAI values.

\section{A. Rainfall Anomaly Index}

Drought indices are essential elements for an efficient drought monitoring system. RAI is one of the commonly adopted indices in the literature due to the advantages offered by RAI for analyzing drought. RAI transforms information of climatic anomalies in an easy way and allow the assessing climatic anomalies in terms of their intensity, duration, frequency and spatial extent [2].

The RAI is a meteorological drought index originally designed by [12], [13]. The RAI strength lies in that it is easy to calculate as it only requires one variable, precipitation, to classify the drought occurrence and severity. It can be calculated in monthly, seasonal or annual time scale. RAI is particularly successful to detect persistence of drought periods [14], and therefore it was adopted by several studies ([15], [16]). The RAI is categorized according to a classification based on its value, which determines the severity of the case from extremely wet to extremely dry as shown in Table I.

TABLE I: RAI CLASSIFICATION

\begin{tabular}{l|l}
\hline Index Value & Character of the weather \\
\hline 4 or more & Extremely wet \\
\hline 3 to 3.99 & Very wet \\
\hline 2 to 2.99 & Moderately wet \\
\hline 1 to 1.99 & Slightly wet \\
\hline 0.99 to -0.99 & Near normal \\
\hline-1 to -1.99 & Mild drought \\
\hline-2 to -2.99 & Moderate drought \\
\hline-3 to -3.99 & Severe drought \\
\hline-4 or less & Extreme drought \\
\hline
\end{tabular}

RAI was computed for positive anomalies using (1) and for negative anomalies using (2).

$$
\begin{gathered}
R A I=+3\left(\frac{R F-M_{R F}}{M_{H 10}-M_{R F}}\right) \\
R A I=-3\left(\frac{R F-M_{R F}}{M_{L 10}-M_{R F}}\right)
\end{gathered}
$$

In Equations $(1,2), \mathrm{RF}$ is the actual rainfall for a given time scale, $M_{R F}$ is mean of the total length of record, $M_{H 10}$ is mean of the ten highest values of rainfall on record, and $\mathrm{M}_{\mathrm{L} 10}$ is the ten lowest values of rainfall on record.

\section{B. Aridity Index}

One more drought index used in this paper as a benchmark is the aridity index (AI). AI was developed by UNESCO [17] and adopted by several studies to categorize the arid lands [18]. AI represents the aridity in a ratio of precipitation $(P)$ to potential evapotranspiration $(P E T)$ and calculated by:

$$
A I=\left(\frac{P}{P E T}\right)
$$

In this study, PET is calculated using Thornthwaite method as done in [19]. Thornthwaite method uses average monthly 
temperature to calculate PET. The AI index classification is shown in Table II.

TABLE II: AI CLASSIFICATION [20]

\begin{tabular}{l|l}
\hline Index Value & Character of the weather \\
\hline 0.03 or less & Hyper-arid \\
\hline 0.03 to 0.20 & Arid \\
\hline 0.20 to 0.50 & Semi-arid \\
\hline 0.50 to 0.65 & Dry sub-humid \\
\hline
\end{tabular}

\section{Trend Analysis}

After calculations of RAI and AI values using observed, and projected near and far future data, non-parametric Mann-Kendal (MK) test was applied to detect trends in this study. It should be noted that trend analysis was applied only for RAI values for the sake of brevity. Non-parametric tests are usually applied for hydro-meteorological data trend analysis, since hydro-meteorological data mostly follow non-normal distribution [10]. The MK test was applied to detect trends in observed and projected RAIs, since MK test was used commonly in hydro-meteorological data trend analysis (e.g., [21-[24]).

MK is a rank based nonparametric test that was developed to detect linear or non-linear trends [25]. The $\mathrm{z}$ test statistics of MK test can be calculated by:

$$
\mathrm{z}= \begin{cases}\frac{S-1}{\operatorname{Var}(S)} & S>0 \\ 0 & S=0 \\ \frac{S+1}{\operatorname{Var}(S)} & S<0\end{cases}
$$

where $S$ is calculated by

$$
\mathrm{S}=\sum_{k=1}^{n-1} \sum_{j=k+1}^{n} \operatorname{sgn}\left(x_{j}-x_{k}\right)
$$

where,

$$
\operatorname{sgn}\left(x_{j}-x_{k}\right)= \begin{cases}1 & \text { if } x_{j}-x_{k}>0 \\ 0 & \text { if } x_{j}-x_{k}=0 \\ -1 & \text { if } x_{j}-x_{k}<0\end{cases}
$$

In Equation (5), $x_{5}-x_{k}$ is the sequential data values, and $n$ is the number of observations. The $\operatorname{Var}(S)$ can be calculated by:

$$
\operatorname{Var}(\mathrm{S})=\frac{n(n-1)(2 n+5)}{18}
$$

In the MK test, positive $\mathrm{z}$-statistics values indicate increasing trends, whereas negative values indicate decreasing trends. If the calculated z-statistics is higher than the critical value at any significance level (i.e., 0.1, 0.05, 0.01 ), the trend is considered statistically significant at the same significance level. It should be noted that trend analysis was applied to monthly index values in this study.

\begin{tabular}{|c|c|c|c|c|c|c|c|c|c|c|c|c|c|c|}
\hline Model Name & $\begin{array}{l}\text { Future } \\
\text { Period }\end{array}$ & $\mathrm{RCP}$ & Jan & Feb & Mar & Apr & May & Jun & Jul & Aug & Sep & Oct & Nov & Dec \\
\hline \multirow{7}{*}{ GISS_E2_H } & \multirow{3}{*}{$\begin{array}{l}\text { Near } \\
\text { future }\end{array}$} & 2.6 & -1.0 & -1.1 & -0.6 & -1.8 & -2.9 & -3.0 & -2.8 & -3.0 & -2.9 & -2.9 & -2.4 & -1.0 \\
\hline & & 4.5 & -1.1 & -1.3 & -0.5 & -1.8 & -2.9 & -3.0 & -2.8 & -3.0 & -2.9 & -2.9 & -2.3 & -1.0 \\
\hline & & 8.5 & -1.1 & -1.2 & -0.6 & -1.7 & -2.8 & -3.0 & -2.8 & -3.0 & -2.9 & -2.8 & -2.3 & -1.0 \\
\hline & \multirow{4}{*}{$\begin{array}{l}\text { Far } \\
\text { future }\end{array}$} & 2.6 & -1.2 & -1.1 & -0.4 & -1.7 & -2.9 & -3.0 & -2.8 & -3.0 & -2.9 & -2.9 & -2.3 & -1.3 \\
\hline & & 4.5 & -1.3 & -0.9 & -0.7 & -1.9 & -2.9 & -3.0 & -2.8 & -3.0 & -2.9 & -2.9 & -2.2 & -1.1 \\
\hline & & 6 & -1.2 & -0.9 & -0.7 & -1.8 & -2.9 & -3.0 & -2.8 & -3.0 & -2.9 & -2.9 & -2.3 & -1.0 \\
\hline & & 8.5 & -1.2 & -0.8 & -0.9 & -1.8 & -2.9 & -3.0 & -2.8 & -3.0 & -2.9 & -2.8 & -2.3 & -1.1 \\
\hline \multirow{7}{*}{ GISS_E2_R } & \multirow{4}{*}{$\begin{array}{l}\text { Near } \\
\text { future }\end{array}$} & 2.6 & -0.7 & -0.9 & -1.1 & -1.9 & -2.9 & -3.0 & -2.8 & -3.0 & -2.9 & -2.8 & -2.3 & -1.1 \\
\hline & & 4.5 & -1.1 & -0.9 & -0.6 & -1.8 & -2.9 & -3.0 & -2.8 & -3.0 & -3.0 & -2.8 & -2.3 & -1.5 \\
\hline & & 6 & -0.9 & -0.6 & -1.1 & -2.1 & -2.9 & -3.0 & -2.8 & -3.0 & -2.9 & -2.8 & -2.3 & -1.2 \\
\hline & & 8.5 & -1.0 & -1.0 & -0.8 & -1.7 & -2.9 & -3.0 & -2.7 & -3.0 & -2.9 & -2.9 & -2.3 & -1.0 \\
\hline & \multirow{3}{*}{$\begin{array}{l}\text { Far } \\
\text { future }\end{array}$} & 2.6 & -1.2 & -0.8 & -0.6 & -1.8 & -2.9 & -3.0 & -2.8 & -3.0 & -3.0 & -2.9 & -2.2 & -1.3 \\
\hline & & 4.5 & -1.0 & -0.6 & -1.6 & -1.6 & -2.9 & -3.0 & -2.7 & -3.0 & -2.9 & -2.9 & -2.2 & -1.2 \\
\hline & & 6 & -0.7 & -0.9 & -0.8 & -2.3 & -2.9 & -3.0 & -2.8 & -3.0 & -2.9 & -2.9 & -2.3 & -1.2 \\
\hline \multirow{8}{*}{ MIROC_ESM_CHEM } & \multirow{4}{*}{$\begin{array}{l}\text { Near } \\
\text { future }\end{array}$} & 2.6 & -0.9 & -1.1 & -0.7 & -1.6 & -2.9 & -3.0 & -2.8 & -3.0 & -2.9 & -2.9 & -2.4 & -1.2 \\
\hline & & 4.5 & -1.1 & -1.0 & -0.6 & -1.5 & -2.8 & -3.0 & -2.8 & -3.0 & -2.9 & -2.9 & -2.5 & -1.2 \\
\hline & & 6 & -1.0 & -0.8 & -0.7 & -1.6 & -2.9 & -3.0 & -2.8 & -3.0 & -2.9 & -2.9 & -2.5 & -1.4 \\
\hline & & 8.5 & -1.0 & -1.1 & -0.5 & -1.4 & -2.8 & -3.0 & -2.7 & -3.0 & -2.9 & -2.9 & -2.4 & -1.5 \\
\hline & \multirow{4}{*}{$\begin{array}{l}\text { Far } \\
\text { future }\end{array}$} & 2.6 & -1.1 & -1.0 & -0.5 & -1.5 & -2.9 & -3.0 & -2.7 & -3.0 & -2.9 & -2.9 & -2.5 & -1.4 \\
\hline & & 4.5 & -1.0 & -1.1 & -0.5 & -1.5 & -2.8 & -3.0 & -2.7 & -3.0 & -2.9 & -2.9 & -2.4 & -1.3 \\
\hline & & 6 & -1.1 & -0.9 & -0.6 & -1.6 & -2.8 & -3.0 & -2.8 & -3.0 & -2.9 & -2.9 & -2.6 & -1.3 \\
\hline & & 8.5 & -1.1 & -1.2 & -0.5 & -1.4 & -2.8 & -3.0 & -2.7 & -3.0 & -2.9 & -2.9 & -2.5 & -1.3 \\
\hline \multirow{8}{*}{ MRI_CGCM3 } & \multirow{4}{*}{$\begin{array}{l}\text { Near } \\
\text { future }\end{array}$} & 2.6 & -0.8 & -0.9 & -1.0 & -2.2 & -2.9 & -3.0 & -2.8 & -3.0 & -2.9 & -2.9 & -2.1 & -1.0 \\
\hline & & 4.5 & -0.8 & -0.9 & -1.0 & -2.1 & -2.9 & -3.0 & -2.8 & -3.0 & -2.9 & -2.9 & -2.1 & -1.0 \\
\hline & & 6 & -0.9 & -1.0 & -0.6 & -2.1 & -2.9 & -3.0 & -2.8 & -3.0 & -2.9 & -2.9 & -2.1 & -1.1 \\
\hline & & 8.5 & -0.8 & -0.9 & -1.0 & -2.2 & -2.9 & -3.0 & -2.8 & -3.0 & -2.9 & -2.9 & -2.1 & -1.0 \\
\hline & \multirow{4}{*}{$\begin{array}{l}\text { Far } \\
\text { future }\end{array}$} & 2.6 & -1.0 & -1.0 & -0.9 & -2.0 & -2.9 & -3.0 & -2.8 & -3.0 & -2.9 & -2.9 & -2.1 & -0.9 \\
\hline & & 4.5 & -0.8 & -0.9 & -1.0 & -1.9 & -2.9 & -3.0 & -2.8 & -3.0 & -2.9 & -2.8 & -2.0 & -1.1 \\
\hline & & 6 & -1.0 & -1.0 & -1.0 & -2.0 & -2.9 & -3.0 & -2.8 & -3.0 & -2.9 & -2.9 & -2.1 & -0.8 \\
\hline & & 8.5 & -1.0 & -0.9 & -0.8 & -2.2 & -2.9 & -3.0 & -2.8 & -3.0 & -2.9 & -2.9 & -2.1 & -0.9 \\
\hline
\end{tabular}

\section{RESUlTS AND DISCUSSION}

\section{A. RAI and AI Results}

TABLE III: MONTHLY MEAN OBSERVED AND FUTURE RAI VALUES 
TABLE IV: MONTHLY MEAN OBSERVED AND FUTURE AI VALUES

\begin{tabular}{|c|c|c|c|c|c|c|c|c|c|c|c|c|c|c|}
\hline Model Name & $\begin{array}{l}\text { Future } \\
\text { Period }\end{array}$ & $\mathrm{RCP}$ & Jan & Feb & Mar & Apr & May & Jun & Jul & Aug & Sep & Oct & Nov & Dec \\
\hline \multirow{8}{*}{ GISS_E2_H } & \multirow{4}{*}{$\begin{array}{l}\text { Near } \\
\text { future }\end{array}$} & 2.6 & 0.8 & 0.9 & 1.2 & 0.2 & 0.0 & 0.0 & 0.0 & 0.0 & 0.0 & 0.0 & 0.1 & 0.8 \\
\hline & & 4.5 & 0.7 & 0.7 & 1.4 & 0.2 & 0.0 & 0.0 & 0.0 & 0.0 & 0.0 & 0.0 & 0.1 & 0.7 \\
\hline & & 6 & 0.8 & 0.8 & 1.0 & 0.1 & 0.0 & 0.0 & 0.0 & 0.0 & 0.0 & 0.0 & 0.1 & 0.8 \\
\hline & & 8.5 & 0.5 & 0.6 & 1.0 & 0.2 & 0.0 & 0.0 & 0.0 & 0.0 & 0.0 & 0.0 & 0.1 & 0.6 \\
\hline & \multirow{4}{*}{$\begin{array}{l}\text { Far } \\
\text { future }\end{array}$} & 2.6 & 0.7 & 1.2 & 1.9 & 0.3 & 0.0 & 0.0 & 0.0 & 0.0 & 0.0 & 0.0 & 0.1 & 0.7 \\
\hline & & 4.5 & 0.4 & 1.1 & 1.1 & 0.1 & 0.0 & 0.0 & 0.0 & 0.0 & 0.0 & 0.0 & 0.1 & 0.6 \\
\hline & & 6 & 0.8 & 0.7 & 1.0 & 0.1 & 0.0 & 0.0 & 0.0 & 0.0 & 0.0 & 0.0 & 0.1 & 0.7 \\
\hline & & 8.5 & 0.3 & 0.8 & 0.6 & 0.1 & 0.0 & 0.0 & 0.0 & 0.0 & 0.0 & 0.0 & 0.0 & 0.4 \\
\hline \multirow{7}{*}{ GISS_E2_R } & \multirow{4}{*}{$\begin{array}{l}\text { Near } \\
\text { future }\end{array}$} & 2.6 & 1.0 & 0.7 & 0.3 & 0.0 & 0.0 & 0.0 & 0.0 & 0.0 & 0.0 & 0.0 & 0.0 & 0.5 \\
\hline & & 4.5 & 0.7 & 1.1 & 0.7 & 0.1 & 0.0 & 0.0 & 0.0 & 0.0 & 0.0 & 0.0 & 0.0 & 0.4 \\
\hline & & 6 & 0.8 & 1.1 & 0.3 & 0.0 & 0.0 & 0.0 & 0.0 & 0.0 & 0.0 & 0.0 & 0.0 & 0.4 \\
\hline & & 8.5 & 0.6 & 0.5 & 0.4 & 0.1 & 0.0 & 0.0 & 0.0 & 0.0 & 0.0 & 0.0 & 0.0 & 0.5 \\
\hline & \multirow{3}{*}{$\begin{array}{l}\text { Far } \\
\text { future }\end{array}$} & 2.6 & 0.5 & 0.8 & 0.6 & 0.1 & 0.0 & 0.0 & 0.0 & 0.0 & 0.0 & 0.0 & 0.0 & 0.4 \\
\hline & & 4.5 & 0.6 & 0.6 & 0.4 & 0.0 & 0.0 & 0.0 & 0.0 & 0.0 & 0.0 & 0.0 & 0.0 & 0.3 \\
\hline & & 6 & 1.1 & 0.7 & 0.4 & 0.0 & 0.0 & 0.0 & 0.0 & 0.0 & 0.0 & 0.0 & 0.0 & 0.4 \\
\hline \multirow{8}{*}{ MRI_CGCM3 } & \multirow{4}{*}{$\begin{array}{l}\text { Near } \\
\text { future }\end{array}$} & 2.6 & 0.7 & 0.6 & 0.4 & 0.0 & 0.0 & 0.0 & 0.0 & 0.0 & 0.0 & 0.0 & 0.1 & 0.5 \\
\hline & & 4.5 & 0.7 & 0.6 & 0.4 & 0.0 & 0.0 & 0.0 & 0.0 & 0.0 & 0.0 & 0.0 & 0.1 & 0.5 \\
\hline & & 6 & 0.5 & 0.5 & 0.3 & 0.0 & 0.0 & 0.0 & 0.0 & 0.0 & 0.0 & 0.0 & 0.1 & 0.5 \\
\hline & & 8.5 & 0.7 & 0.5 & 0.3 & 0.0 & 0.0 & 0.0 & 0.0 & 0.0 & 0.0 & 0.0 & 0.1 & 0.5 \\
\hline & \multirow{4}{*}{$\begin{array}{l}\text { Far } \\
\text { future }\end{array}$} & 2.6 & 0.6 & 0.6 & 0.4 & 0.0 & 0.0 & 0.0 & 0.0 & 0.0 & 0.0 & 0.0 & 0.1 & 0.6 \\
\hline & & 4.5 & 0.5 & 0.5 & 0.3 & 0.0 & 0.0 & 0.0 & 0.0 & 0.0 & 0.0 & 0.0 & 0.1 & 0.4 \\
\hline & & 6 & 0.5 & 0.5 & 0.3 & 0.0 & 0.0 & 0.0 & 0.0 & 0.0 & 0.0 & 0.0 & 0.1 & 0.7 \\
\hline & & 8.5 & 0.6 & 0.5 & 0.2 & 0.0 & 0.0 & 0.0 & 0.0 & 0.0 & 0.0 & 0.0 & 0.1 & 0.5 \\
\hline \multicolumn{3}{|l|}{ Observed } & 0.7 & 0.7 & 0.5 & 0.1 & 0.0 & 0.0 & 0.0 & 0.0 & 0.0 & 0.0 & 0.0 & 0.5 \\
\hline
\end{tabular}

Table III shows monthly average RAI values for observed, near and far future for four different models (i.e., GISS_E2_H, GISS_E2_R, MIROC_ESM_CHEM, MRI_CGCM3) under four RCPs $(2.6,4.5,6,8.5)$, whereas Table IV illustrates observed and projected (using data from three global climate models including GISS_E2_H, GISS_E2_R and MRI_CGCM3) AI values.

As can be seen from Table III, the RAI values vary between -0.4 and -3 . According to the classification (shown in Table I), RAI range indicates near normal conditions to severe drought. The wettest month with the value of -0.4 is March in the near future according to GISS_E2_H model, and the lowest RAI value, which indicates a severe drought, is -3 for June in all years (near and far future) for all models and all RCPs, since June has zero precipitation for all years.

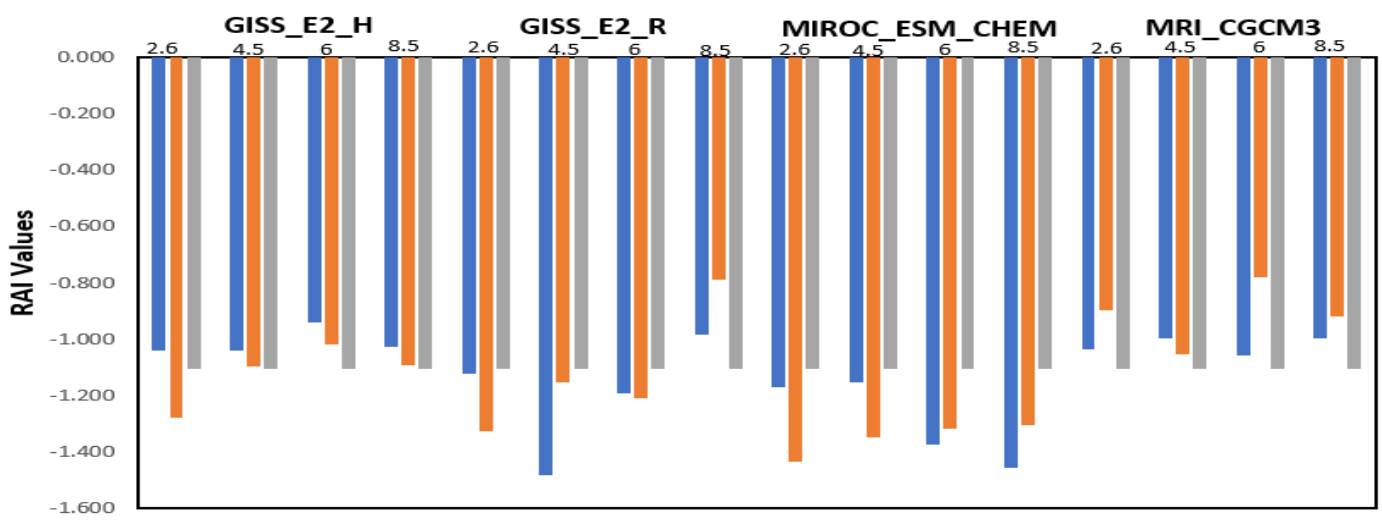

(a) December RAI Values

near Future mar Future m Observed

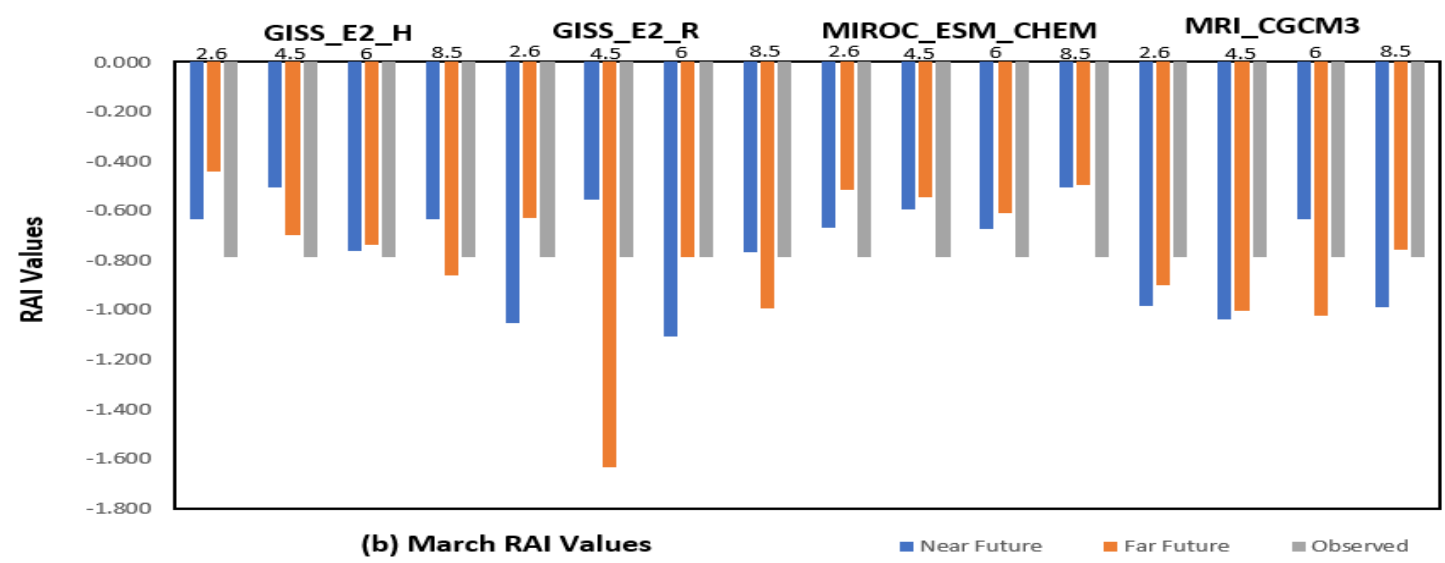

Fig. 2. Projected and observed RAI values in months December and March. 
No clear pattern was found based on comparison between mean monthly RAI values derived for future periods and observed monthly RAI values. Also, comparison between far future RAI values with near future RAI values resulted in no clear pattern. It is worth to note that January and August are the months almost all models (four GCMs) resulted similar results. In January, far future RAI values are higher than near future RAI values, whereas in August, near future RAI values are higher than far future RAI values almost for all models and RCPs. Tabulated information in Table I, was shown graphically in Fig. 2 for months December and March (as an example).

As shown in Table IV, for the months from May to September, observed AI (derived using observed data) indicated hyper-arid conditions. In future, there will be no change in these months in terms of aridity (will stay as hyper -arid) according to AI projections. Winter season months in future will stay as humid based on projected AIs (similar to observed AIs) with minor exceptions including the December month (according to GISS_E2_R) and January month (according to GISS_E2_H for far future under RCP 8.5), which will be semi-arid. GISS_E2_H and GISS_E2_R models will give more humid conditions in comparison with MRI_CGCM3 model. AIs showed that, in general, there will no dramatic pattern change in drought conditions in future.

\section{B. Trend Analysis Results}

TABLE V: MK Z-STATISTICS FOR MONTHLY RAI VALUES

\begin{tabular}{|c|c|c|c|c|c|c|c|c|c|c|c|c|c|}
\hline & & Jan & Feb & Mar & Apr & May & Jun & Jul & Aug & Sep & Oct & Nov & Dec \\
\hline & Observed & 0.98 & -1.51 & $-2.357(0.95)$ & -0.82 & -0.60 & & -0.58 & 0.00 & 0.28 & -0.01 & 1.32 & -0.57 \\
\hline \multirow{4}{*}{ 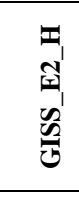 } & RCP 2.5 & 0.23 & -0.90 & -1.35 & -0.22 & -0.44 & N/A & -0.44 & -0.02 & 0.20 & -0.02 & 1.07 & -0.84 \\
\hline & RCP 4.5 & 0.14 & -0.38 & $-2.038(0.95)$ & -0.74 & -0.42 & N/A & -0.40 & 0.02 & 0.22 & -0.01 & 1.15 & -0.60 \\
\hline & RCP 6 & -0.06 & -0.63 & -1.55 & -0.29 & -0.43 & N/A & -0.44 & 0.02 & 0.20 & -0.01 & 0.75 & -0.63 \\
\hline & RCP 8.5 & 0.34 & -0.51 & -0.21 & -0.86 & -0.44 & N/A & -0.39 & 0.02 & 0.22 & -0.01 & 0.77 & -0.61 \\
\hline \multirow{4}{*}{ 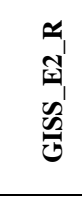 } & RCP 2.5 & -0.68 & -0.90 & -1.01 & -0.23 & -0.43 & N/A & -0.45 & 0.02 & 0.07 & -0.02 & 0.89 & -0.96 \\
\hline & RCP 4.5 & 1.04 & -0.64 & $-3.123(0.01)$ & -0.24 & -0.44 & N/A & -0.38 & 0.02 & 0.22 & -0.02 & 1.22 & 0.13 \\
\hline & RCP 6 & 1.21 & -1.53 & -0.92 & -1.05 & -0.44 & N/A & -0.40 & 0.02 & 0.20 & -0.36 & 0.87 & -0.57 \\
\hline & RCP 8.5 & 1.18 & -1.14 & $-2.109(0.05)$ & -1.64 & -0.42 & N/A & -0.42 & 0.02 & 0.07 & -0.02 & 0.97 & -0.05 \\
\hline \multirow{4}{*}{ 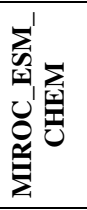 } & RCP 2.5 & 0.35 & -0.81 & -1.40 & -0.38 & -0.42 & N/A & -0.40 & 0.02 & 0.22 & -0.01 & 0.75 & -0.87 \\
\hline & RCP 4.5 & 0.99 & -1.23 & -1.49 & -0.47 & -0.42 & N/A & -0.40 & 0.02 & 0.21 & -0.01 & 1.14 & -0.82 \\
\hline & RCP 6 & 0.40 & -1.27 & -1.46 & -0.52 & -0.42 & N/A & -0.44 & 0.02 & 0.20 & -0.02 & 0.79 & -0.18 \\
\hline & RCP 8.5 & 0.55 & -1.31 & -1.53 & -0.78 & -0.44 & N/A & -0.44 & 0.02 & 0.22 & -0.02 & 0.79 & -0.01 \\
\hline \multirow{4}{*}{$\sum_{\underbrace{\prime}}^{\infty}$} & RCP 2.5 & 0.27 & -1.26 & -1.43 & -0.24 & -0.42 & N/A & -0.45 & 0.02 & 0.22 & -0.02 & 0.83 & -0.12 \\
\hline & RCP 4.5 & 0.66 & -0.92 & -1.49 & -0.21 & -0.44 & N/A & -0.44 & 0.02 & 0.22 & -0.01 & 1.03 & -0.59 \\
\hline & RCP 6 & 0.50 & -1.27 & $-2.297(0.05)$ & -0.26 & -0.44 & N/A & -0.44 & -0.02 & 0.20 & -0.02 & 1.04 & 0.01 \\
\hline & RCP 8.5 & 0.37 & -1.23 & -1.26 & -0.72 & -0.42 & N/A & -0.45 & -0.02 & 0.21 & -0.01 & 1.05 & -0.21 \\
\hline
\end{tabular}

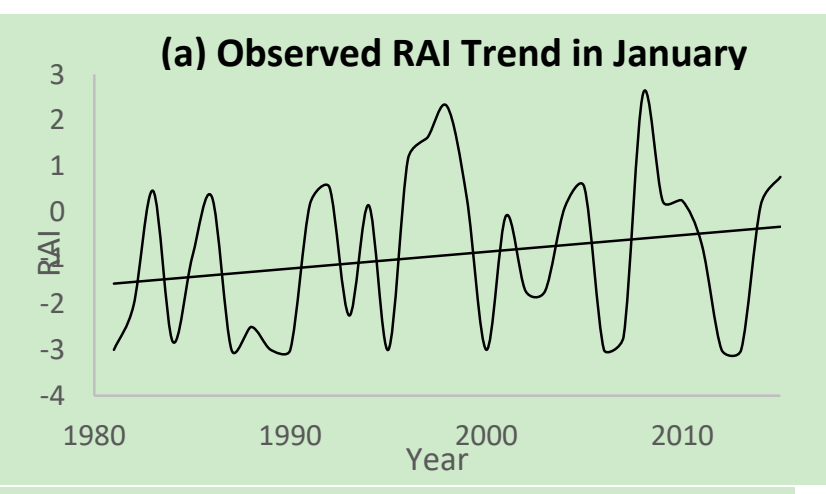

(c) Observed RAI Trend in March

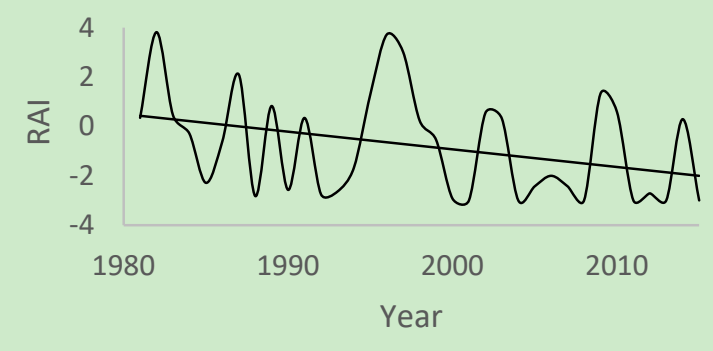

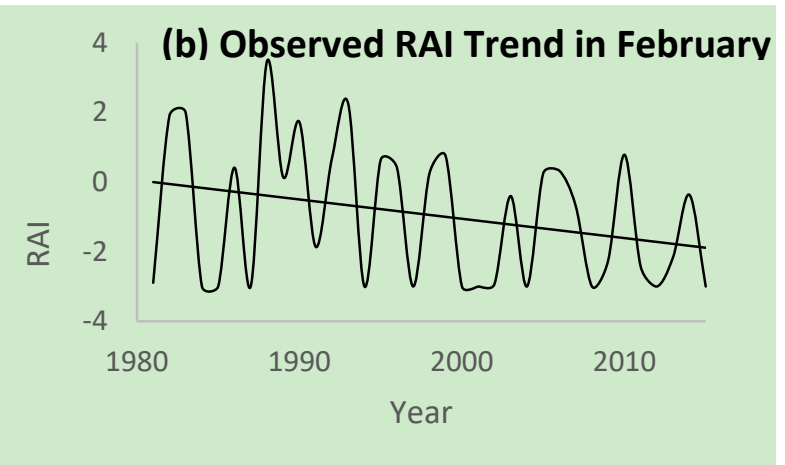

(d) Observed RAI Trend in

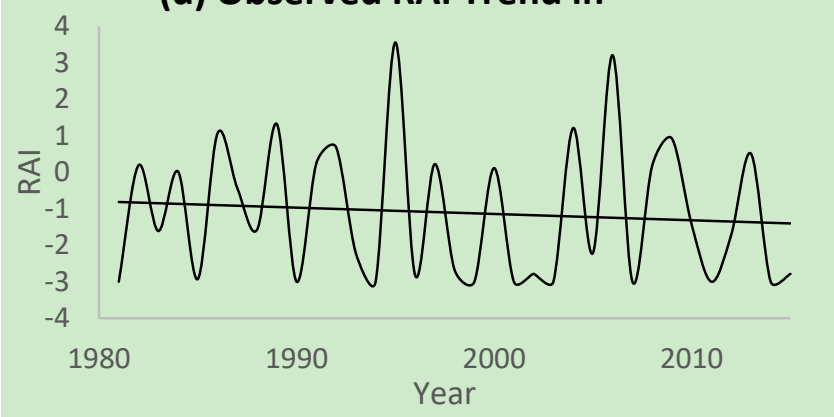

Fig. 3. RAI time series plots for selected months. 
As explained in the Methodology section, MK trend test was applied to RAI values in this study. In Table V, MK test Z-statistics were shown for monthly observed and future (near and far future were analyzed as a single future time series data) RAI values.

In Table $\mathrm{V}, \mathrm{z}$-statistics indicating statistically significant trends were shown in bold characters along with significance levels (0.05 [95\% significance] and 0.01 [99\% significance]). It should be noted that in June no z-statistics value was found, since this monthly is completely dry both for observed and projected future RAIs. Also, for other dry months, MK Z-statistics did not show much variation over years. Considering MK is a rank based non-parametric test, $\mathrm{z}$-statistics are not very reliable for the dry months from May to October.

As can be seen in Table V, decreasing observed and future RAI trends were found in February, March, April and December months, whereas increasing RAI trends were detected in November and January months. However, only decreasing RAI trends in March for observed, GISS_E2_H (under RCP 4.5), GISS_E2_R (under RCPs 4.5 and 8.5), and MRI_CGCM3 (under RCP 6) were statistically significant.

Fig. 3 illustrates time series plots and trend lines for observed RAI values in January, February, March and December months.

As explained before, February and March are the wettest months in Sharjah, and decreasing trends were detected for RAI values in February and March both for observed and future periods, and some of the detected decreasing trends in March is statistically significant. Decreasing trends in RAIs in wet months indicate further drying in wet season in Sharjah. This may cause significant adverse effects on agriculture activities in Sharjah. More negative RAI values (caused by decreased precipitation) results in lower recharge of groundwater aquifers in Sharjah.

\section{CONClusions}

In this study, drought intensity in Sharjah were assessed using RAI and AI derived from monthly observed and projected (through GCMs) rainfall data. The projections were made for two different future periods: near future for the period of 2030- 2064 and far future for the period of 2065-2099 under different greenhouse gas emission scenarios (RCPs). Following calculation of observed and projected RAIs, MK trend test was used to detect observed and projected RAI trends.

No clear relationship was found based on comparison of observed and projected data. It is not possible to state that future will be drier or wetter for all months. However, decreasing trends in RAIs (drier future) were detected for wettest two months (February and March). Drier conditions in February and March months may cause significant problems in particular for agricultural activities.

It should be noted that this study is an initial stage of a project. In further steps, more complex drought indices, considering streamflow and soil moisture data in calculations, will be applied. In this study, observed data from a single station was used. Data from more observation stations over UAE will be used and drought assessment will be conducted for entire UAE in future steps of the project. This study provides useful information to policymakers in UAE for better drought management in Sharjah, UAE.

\section{CONFLICT OF INTEREST}

The authors declare no conflict of interests.

\section{AUTHOR CONTRIBUTIONS}

Abdullah G. Yilmaz supervised the analysis and wrote the paper, Arwa Najah, Aysha Hussein and Athra Khamis contributed in data collecting and analysis, Naseraldin Kayemah and Serter Atabay assisted in reviewing the paper.

\section{REFERENCES}

[1] M. Azarakhshi, M. Mohammad, A. Hosein, and A. Hasan, "Assessment of the Palmer drought severity index in arid and semi arid rangeland: (Case study: Qom province, Iran)," pp. 77-86, Dec. 2011.

[2] D. A. Wilhite, "Drought as a natural hazard: concepts and definitions," Drought: A Global Assessment, vol. 1, Routledge, New York, pp. 1-18, 2000.

[3] R. Restuccia, 5 Causes of Drought, 2016.

[4] W. H. Nam, M. J. Hayes, M. D. Svoboda, T. Tadesse, and D. A. Wilhite, "Drought hazard assessment in the context of climate change for South Korea," Agricultural Water Management, vol. 160, pp. 106-117, Oct. 2015.

[5] A. Loukas, L. Vasiliades, and J. Tzabiras, "Climate change effects on drought severity," Advances in Geosciences, vol. 17, pp. 23-29, June 2008 .

[6] World Bank, Water in the Arab World: Management Perspectives and Innovations, 2009.

[7] MOCCAE, National Climate Change Plan of the United Arab Emirates 2017-2050, Abu Dhabi, 2017.

[8] M. AlEbri, H. Arman, and A. Shalaby, "The impact of El Niño and La Niña on the United Arab Emirates (UAE) rainfall," General Scientific Researches, vol. 4, pp. 5-10, 2016.

[9] M. Sherif, M. Almulla, A. Shetty, and R. K. Chowdhury, "Analysis of rainfall, PMP and drought in the United Arab Emirates," International Journal of Climatology, vol. 34, pp. 1318-1328, 2014.

[10] A. G. Yilmaz and A. G. Shabib, "Rainfall and air temperature projections for Sharjah City, United Arab Emirates," International Journal of Water, vol. 13, no. 1, pp. 60-79, 2019.

[11] I. Jubb, P. Canadell, and M. Dix, "Representative concentration pathways (RCPs)," Australian Government, Department of the Environment, 2013.

[12] M. P. Rooy, "A rainfall anomaly index (RAI) independent of time and space," Notos, vol. 14, pp. 43-48, 1965.

[13] J. Keyantash and J. A. Dracup, "The quantification of drought: an evaluation of drought indices," Bulletin of the American Meteorological Society, vol. 83, pp. 1167-1180, Aug. 2002.

[14] K. Tilahun, "Analysis of rainfall climate and evapo-transpiration in arid and semi-arid regions of Ethiopia using data over the last half a century," Journal of Arid Environments, vol. 64, pp. 474-487, Feb. 2006.

[15] A. Loukas, L. Vasiliades, and N. R. Dalezios, "Intercomparison of meteorological drought indices for drought assessment and monitoring in Greece," in Proc. the International Conference on Environmental Science and Technology, vol. 2, pp. 484-491, Sep. 2003.

[16] D. Dutta, A. Kundu, N. R. Patel, S. K. Saha, and A. R. Siddiqui, "Assessment of agricultural drought in Rajasthan (India) using remote sensing derived Vegetation Condition Index (VCI) and Standardized Precipitation Index (SPI)," The Egyptian Journal of Remote Sensing and Space Science, vol. 18, pp. 53-63, Jun. 2015.

[17] UNESCO, "Map of the world distribution of arid regions," $M A B$ Techn., Note 7, 1979.

[18] D. Onder, M. Aydin, S. Berberoğlu, S. Onder, and T. Yano. "The use of aridity index to assess implications of climatic change for land cover in Turkey," Turkish Journal of Agriculture and Forestry, vol. 33, pp. 305-314, Aug. 2009.

[19] P. T. Nastos, N. Politi, and J. Kapsomenakis. "Spatial and temporal variability of the Aridity Index in Greece," Atmospheric Research, vol. 119, pp. 140-152, Jan, 2013.

[20] R. Maliva and T. Missimer. "Arid lands water evaluation and management," Springer Science \& Business Media, Jun. 2012.

[21] O. U. Laz, A. Rahman, A. Yilmaz, and K. Haddad. "Trends in sub-hourly, sub-daily and daily extreme rainfall events in eastern 
Australia," Journal of Water and Climate Change, vol. 5, pp. 667-675, Dec. 2014.

[22] A. G. Yilmaz, "The effects of climate change on historical and future extreme rainfall in Antalya, Turkey," Hydrological Sciences Journal, vol. 60, pp. 2148-2162, Dec. 2015

[23] A. G. Yilmaz, "Climate change effects and extreme rainfall non-stationarity," in Proc. the Institution of Civil Engineers-Water Management, vol. 170, pp. 57-65, Mar, 2016.

[24] M. A. Imteaz, W. Mahmood, K. A. Sagar, and A. Yilmaz, "Climate change fingerprints in lower Euphrates basin: Climate and flow data trend analysis," International Journal of Water, vol. 11, pp. 279-293, Aug. 2017

[25] M. Shadmani, S. Marofi, and M. Roknian, "Trend analysis in reference evapotranspiration using Mann-Kendall and Spearman's Rho tests in arid regions of Iran," Water Resources Management, vol. 26, pp. 211-224, Jan. 2012.

Copyright $(92020$ by the authors. This is an open access article distributed under the Creative Commons Attribution License which permits unrestricted use, distribution, and reproduction in any medium, provided the original work is properly cited (CC BY 4.0).

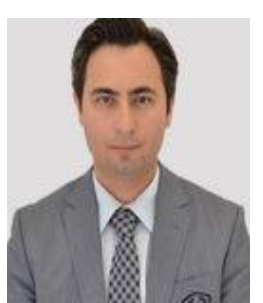

Abdullah Gokhan Yilmaz has a $\mathrm{PhD}$ in civil (water) engineering from the Swinburne University of Technology, Australia. He is currently working at the University of Sharjah in Civil and Environmental Engineering Department. His research interests are climate change hydrology, rainfall-runoff modelling, GIS and remote sensing applications in water resources management and extreme rainfall, flood and drought analysis. He has delivered variety of courses at undergraduate and graduate levels including water resources engineering, fluid mechanics, hydraulic engineering and design, engineering economics, irrigation water management and GIS in water resources engineering.

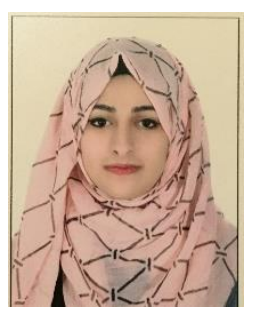

Arwa Najah is a research student in Civil and Environmental Engineering Department at University of Sharjah. She is also working as a research assistant at University of Sharjah, and she is assisting projects on climate change hydrology, drought and flood monitoring and assessment.

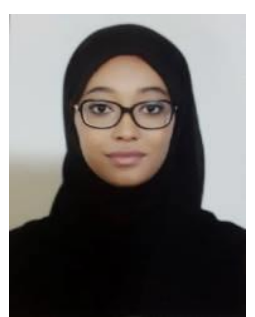

Aysha Hussein is a research student in Civil and Environmental Engineering Department at University of Sharjah. Her research interests are the assessment of climate change models, extreme weather events and spatio-temporal analysis of hydro-meteorological data in particular using GIS softwares.

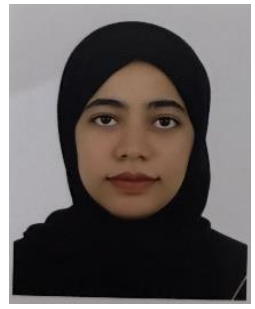

Athra Khamis is a research student in Civil and Environmental Engineering Department at University of Sharjah. She is working as a research assistant with a particular contribution on $\mathrm{R}$ programming language use in drought index calculation and assessment.

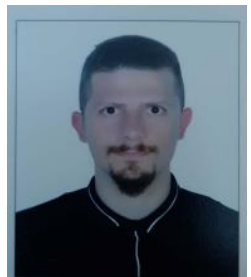

Naseraldin Kayemah is a master of research student in Civil and Environmental Engineering Department at University of Sharjah. His research interests are statistical assessment of hydro-meteorological variables and groundwater hydrology. He is currently working as a research assistant and working on spatio-temporal assessment of groundwater resources in United Arab Emirates.

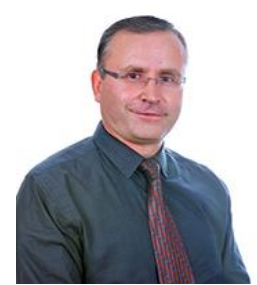

Serter Atabay has more than seven years of professional experience with the UK's leading specialists in flood risk and environmental management. He has taught a variety of courses for undergraduate students, including fluid mechanics, water resources engineering, coastal engineering and statics. His general area of specialization is open channel hydraulics, and his research interests span over a few sub-areas of research including compound channel flow mechanism and boundary shear stress distributions, and hydraulic structures such us bridges and culverts. 